\title{
Changes in drug treatment after discharge from hospital in geriatric patients
}

\author{
Rachel Ann Cochrane, Asit R Mandal, Margaret Ledger-Scott, Roger Walker
}

\begin{abstract}
Objectives-To ascertain changes in drug treatment of elderly patients after discharge from hospital and to identify areas of communication which may require improvement.
\end{abstract}

Design-Follow up of patients six to 14 days after discharge, when the drugs supplied by the hospital should have run out and a further supply obtained from the general practitioner. Patients were also asked about information supplied to them by health care professionals during their hospital stay.

Subjects -50 elderly patients discharged from five geriatric wards (mean age 76.9 years).

Setting-Sunderland District Health Authority.

Main outcome measure-Drugs taken after discharge from hospital.

Results - After returning home the drug regimen of 45 patients differed from that prescribed on discharge from hospital, with 11 patients taking a different dose, 10 having stopped drugs, and 20 taking new drugs. Possible influencing factors included an incomplete drug history, the continuation of drugs taken before hospital admission, and changes in the prescription not attributable to a conscious clinical decision. Lack of information also contributed; 46 patients could not recall being told when to take drugs before discharge.

Conclusion-Closer communication is needed between hospital and community health care professionals to ensure that patients are informed about their discharge prescription and continuation of treatment.

Sunderland District General Hospital, Sunderland SR4 7TP Rachel Ann Cochrane, community services pharmacist Asit R Mandal, consultant geriatrician

Royal Infirmary, Sunderland SR2 7JE

Margaret Ledger-Scott,

dispensory manager

School of Pharmaceutical and Chemical Sciences, Sunderland Polytechnic, Sunderland SR2 7EE Roger Walker, teacher practitioner

Correspondence to: Mrs R A Cochrane, Pharmacy Department, Grange Park Clinic,

Monkwearmouth Hospital Sunderland.

BMF 1992;305:694-6

\section{Introduction}

Poor compliance of patients with medication may jeopardise treatment. Poor compliance is usually attributed to the patient either not understanding the drug regimen or choosing to deviate from it. But after discharge from hospital there are several other possible reasons for poor compliance, some of which are out of control of the patient.

We investigated the reasons why patients may deviate from prescribed drug treatment after discharge from hospital. The objectives of the study were to follow up patients discharged from hospital into the community to observe whether their drug regimen changed; to investigate the information given to patients by health care professionals with respect to drugs and identify areas for improvement; and to identify communication between health care professionals which could benefit the patient.

\section{Subjects and method}

We studied patients discharged from five geriatric wards in Sunderland District General Hospital. All patients were under the care of a consultant geriatrician
(ARM) and were discharged with two or more drugs to their own home or that of a relative or friend. All patients (and where appropriate relatives) who gave permission for a home visit were accepted into the study. Fifty patients fulfilled these criteria over the 12 month study period.

Discharge drugs were usually issued by sending a triplicate prescription to the hospital pharmacy. The hospital pharmacy would supply sufficient drugs for five days. Patients were given the drugs on the ward immediately before going home together with a copy of the prescription and written instructions to take it to the general practitioner. To ensure continuity of treatment it was important that patients obtained a further supply of drugs from their general practitioner not later than the fifth day after discharge.

A pharmacist (RAC) visited each patient's home six to 14 days after discharge from the hospital-that is, after the initial supply of drugs given by the hospital should have been finished and a further supply obtained from the general practitioner.

During the home visit, a structured verbal questionnaire was used to elicit information about the drugs. Wherever possible all drugs held by the patient at the time of the visit were inspected, including those prescribed before hospital admission, those issued by the hospital, and those obtained from the general practitioner after discharge. The prescription issued on discharge and the drugs actually being taken by the patient at home after discharge were compared.

Patients were asked about information offered to them by health care professionals during their hospital stay, including details of whether they had been informed about the number of days' treatment supplied on discharge; whether they had been advised to obtain a further supply from their general practitioner before the drugs provided by the hospital were finished; and whether information had been supplied about the purpose of their drugs, when to take them, or possible side effects. The study was approved by the hospital and general practice ethics committees of Sunderland Health Authority.

\section{Results}

Fifty patients (mean age 76.9 years) were visited at home. Their mean length of stay in the geriatric wards had been 11.7 days. A relative or friend answered the questionnaire on behalf of 10 patients; nine of these patients had their drugs supervised by the relative or friend. Of the 40 patients who answered the questionnaire themselves, four received supervised medication from a friend or relative.

\section{CHANGES IN DRUGS OBTAINED AFTER DISCHARGE}

Table I shows the differences between discharge drugs and those subsequently obtained from the general practitioner. For 22 patients the name of the 
TABLE I-Changes in prescriptions given to elderly patients after discharge from hospital

\begin{tabular}{lcc}
\hline Detail changed & $\begin{array}{c}\text { No of patients } \\
(\mathrm{n}=50)\end{array}$ & No of drugs \\
\hline Drug name & 22 & 25 \\
Expression of strength & 1 & 2 \\
Directions for taking & 11 & 14 \\
Specific instructions changed to & 7 & 11 \\
as directed & 11 & 12 \\
Dose & 10 & 13 \\
Drug stopped & 20 & 29 \\
New drug started &
\end{tabular}

drug had been changed to a proprietary name-for example, isosorbide mononitrate changed to Elantan or Monit (also with possible appearance change), ranitidine to Zantac, buprenorphine to Temgesic, and nifedipine to Adalat. Eleven of these patients had been seen by the general practitioner after returning home from hospital.

For one patient the expression of strength on the label had been changed for two drugs (from 62.5 microgram to $0.06253 \mathrm{mg}$ and from SR tabs to tabs). This patient had not been seen by the general practitioner.

Directions for taking drugs were altered for 14 drugs (11 patients), although the overall dose remained the same-for example, glibenclamide to be taken at 7.30 am changed to morning, frusemide $80 \mathrm{mg}$ daily changed to $40 \mathrm{mg}$ twice daily, phenytoin $200 \mathrm{mg}$ at night to $100 \mathrm{mg}$ twice daily, glibenclamide $15 \mathrm{mg}$ in the morning to $5 \mathrm{mg}$ three times daily. None of these patients had been reviewed by the general practitioner.

For 11 drugs (seven patients) the label stated "as directed" rather than giving the specific directions written on the copy of the discharge prescription. Doses had been changed for 12 drugs in 11 patientsfor example, slow release sodium one twice daily to one three times daily; prednisolone $5 \mathrm{mg}$, two twice daily to one twice daily. Only five of these 18 patients had been seen by the general practitioner after discharge.

Thirteen drugs taken by 10 patients on discharge were discontinued after their return home. Five of these patients had been reviewed by the general practitioner, two of whom had stopped all drugs provided at discharge because their general practitioner had advised them to use up drugs prescribed before hospital admission, although they were different.

Twenty nine new prescribed drugs were being taken by 20 patients on their return home-for example, laxatives, topical preparations, analgesics, or a substitute for a drug prescribed at discharge. The general practitioner had seen 10 of these patients.

\section{DRUGS TAKEN BEFORE HOSPITAL ADMISSION}

Sixteen patients had a total of 33 drugs issued before admission but which were not taken after returning home; 16 of these drugs were not noted on admission to hospital. There were 18 patients taking 40 drugs that had been issued before hospital admission. Two patients continued treatment on the advice of the general practitioner (11 drugs), 15 patients decided themselves to continue ( 26 drugs), and one patient continued on the advice of a relative (three drugs).

Those drugs that patients had decided to continue taking included three drugs that had been discontinued in hospital and 20 that hospital staff had not known were being taken by the patient - that is, omitted from notes on admission. Examples included trimipramine (this was not noted on admission to hospital), tiaprofenic acid (this had been intentionally discontinued in hospital and ranitidine started), and hypromellose and acetylcysteine eye drops (these had been kept in a handbag in the ward unknown to staff).
Of the 40 drugs taken before admission and continued on returning from hospital, 29 had not been noted on admission to hospital, 30 were different from those prescribed on discharge from hospital, two were the same drugs as those prescribed on discharge but at a different dose, and two were the same drugs but with different names.

There were 23 over the counter preparations taken regularly by 12 patients. However, only one of these (Benylin) had been noted on admission. These included Setlers, Beechams Hot Lemon, paracetamol, Maalox suspension, Anusol cream, and boracic powder for eye bath.

\section{INFORMATION RECEIVED BY THE PATIENT}

Table II shows the information about discharge drugs offered by health care professionals to patients during their stay on the ward. On returning home, 39

TABLE II - Information about drugs given to 50 patients in hospital

\begin{tabular}{lccc}
\hline & Not informed & $\begin{array}{c}\text { Informed by } \\
\text { nurse }\end{array}$ & $\begin{array}{c}\text { Informed by } \\
\text { doctor }\end{array}$ \\
\hline Amount supplied & 29 & 21 & \\
Obtain further supply & 30 & 20 & \\
Purpose & 41 & 9 & \\
When to take & 46 & 4 & 3 \\
Side effects & 47 & & \\
\hline
\end{tabular}

patients received a further supply of drugs from their general practitioner before finishing those supplied on discharge; six received a further supply after finishing their discharge prescription (this meant an interruption to their regimen), and five had not received a further supply at all. All further drugs received had been dispensed by a community pharmacist, with 29 patients claiming that they usually took their prescriptions to the same community pharmacist.

\section{Discussion}

For 45 patients, there was a lack of continuity in one or more aspects between drugs taken after leaving hospital and those provided on discharge from hospital. This included changes in drug, drug name, strength, and dosage instructions and additions to or discontinuation of drugs. Most of the patients had not been reviewed by their general practitioner and so these changes could not be attributed to clinical judgment. Different drugs were added on return home, even though patients had not been seen by the general practitioner. This could be attributed to patients asking for previous drugs, which were added to the prescription by the receptionist, or to drugs recorded on manual or computerised records not being deleted. The availability of drugs prescribed before admission was also an influencing factor.

Several studies have highlighted the value of self treatment for inpatients. ${ }^{1-4}$ However, our study suggests that time spent on self treatment would be wasted as the elderly patients would be confused by changes after discharge, even if the overall dose was the same or the same drug was given but under a different name.

\section{AVOIDING PRESCRIPTION CHANGES}

A possible solution to the problems shown by our study would be to follow up patients after discharge into the community to identify discrepancies and liaise with general practitioners and community pharmacists. Community pharmacists could also receive a copy of the discharge prescription, which would enable them to query whether changes in subsequent prescriptions were intentional and to counsel patients accordingly. 
This would require greater communication between the hospital and community and the general practitioner and community pharmacist, possibly through a hospital based liaison pharmacist.

Of the 96 prescribed and non-prescription drugs retained at home by the patients, only 29 were documented in the patients' notes on admission to hospital. This indicates a lack of communication between the community and hospital. Information may be obtained from relatives, friends, wardens, or ambulance crew, who may or may not bring drugs found at the home; even if drugs are brought to hospital some may be missed. If the general practitioner attends the patient at home in an emergency a complete drug history may not be available. Therefore hospital medical staff may not be aware of important drugs that need to be continued or should not be stopped abruptly or which may have contributed to the patients admission. One study has shown that both prescribed and non-prescription drugs can cause illness requiring admission to hospital, especially in elderly patients.

Pharmacists have a valuable role in taking drug history. ${ }^{6}$ With the establishment of patient medication records $^{7}$ the community pharmacist may be able to provide a drug history for the hospital. However, a complete history could be guaranteed only if the patient visited just one pharmacy or if patients were registered with a particular community pharmacist. A study based in the West Midlands showed that $62 \%$ of the general population visited the same community pharmacist for their prescription, ${ }^{8}$ and for the geriatric population of a Merseyside study this figure rose to $87 \cdot 2 \% .^{9}$

\section{PROVIDING INFORMATION}

After returning home, patients recalled little information being given about drugs while in hospital. If any information had been given it was usually by nursing staff. Either the patients did not recall what they were told (in which case communication was ineffective), or health care professionals assumed that the patient was already aware of essential information. Another possibility is that the patient was considered unable to understand information about the drugs. Lack of understanding of a drug regimen may lead to deviation from prescribed treatment. ${ }^{10}$ Counselling by a pharmacist, alone or with written information, ${ }^{11-13}$ has been shown to improve patient understanding and reduce errors.

\section{CONCLUSIONS}

Our study highlights the changes in treatment that occur after discharge from hospital into the community. In many cases these changes could not be attributed to a conscious clinical decision. Factors influencing these changes included an incomplete drug history on admission to hospital; patients not receiving information during hospital stay; the continuation of drugs taken before hospital admission; changes in drug name, dosage, and directions; and the addition or discontinuation of drugs after discharge. The continuity may also be disrupted if the patient does not obtain a further supply before the discharge prescription runs out. A working party has been set up in Sunderland to look at ways of ensuring continuity of treatment after discharge from hospital. Lack of continuity wastes resources spent stabilising patients on drugs. Closer communications between all health care professionals and between hospital and the community are therefore required to ensure this continuity and that patients are informed and aware of their treatment so that individualised regimens are not jeopardised.

1 Davidson JR. Trial of self-medication in the elderly. Nursing Times 1974;70: 391-2.

2 Hatch AM, Tapley A. A self-administration system for elderly patients at Highbury Hospital. Nursing Times 1982;78:1773-4.

3 Walker CA, Martin PC. Self medication for the elderly in-patient. British Fournal of Pharmaceutical Practice 1987;9:47-52.

4 Corrigan MS. Primary pharmacy - a patients' self-help service. Pharmaceutical Foumal 1989;243:458-60.

5 Caranosos CJ, Stuart RB, Cluff LE. Drug-induced illness leading to hospitalization. FAMA 1974;228:713-7.

6 Dodds LJ. An objective assessment of the role of the pharmacist in medication and compliance history taking. British fournal of Pharmaceutical Practice 1982;4:12-24.

7 Stevens $\mathbf{R}$. The evolution of patient medication records in British community pharmacy. International fournal of Pharmaceutical Practice 1991;1:64-72.

8 Milburn LJ, Dunbar PE, Kendall HE. Factors influencing pharmacy patronage in the West Midlands. Pharmaceutical fournal 1990;245:R19.

9 Mottram DR, Ford JL, Markey B, Mitchelson K. Public perceptions of community pharmacy. Pharmaceutical fournal 1989;243:R14-7.

10 Parkin DM, Henney CR, Quirk J, Crooks J. Deviation from prescribed drug treatment after discharge from hospital. BMf 1976;ii:686-8.

11 Macdonald ET, Macdonald JB, Phoenix M. Improving drug compliance after hospital discharge. $B M \mathcal{F}$ 1977;ii:618-21.

12 Sweeney SJ, Dixon JS, Sutcliffe I. The impact of the clinical pharmacist on compliance in a geriatric population. Pharmaceutical foumal 1989;242: R4-6.

13 Winfield AJ, Owen CJ. Information leaflets: a means of improving patient compliance. British foumal of Pharmaceutical Practice 1990;12:206-9.

(Accepted 14 August 1992) 